\title{
Clinical studies of workers exposed to polyvinylchloride dust
}

\author{
CA SOUTAR, S GAULD \\ From the Institute of Occupational Medicine, Edinburgh
}

ABSTRACT A previous study showed that exposure of workers to polyvinylchloride (PVC) dust $\stackrel{\infty}{\oplus}$ was associated with the presence of small rounded opacities in the chest radiograph, and also with a small average reduction of the forced expiratory volume in one second $\left(F E V_{1}\right)$. Studies have now been carried out on selected men to determine the clinical importance of the presence of small rounded opacities and also to identify any clinical or physiological features associated with PVC dust exposure. Among 28 men with small rounded opacities, complaints of persistent bronchial mucous hypersecretion were more common (nine men) than among 29 men of similar age, smoking habits, and dust exposures (one man, $p<0.01$ ), and there was a suggestion that the physical sign of late inspiratory crackles was more frequent among men with opacities (seven of 27 men) than the other men (two of 28 men, $p<0.06$ ). The average lung function of men with opacities was only trivially lower than that of the comparative group and the difference between the groups was not significant. In further studies 13 non-smokers with the highest PVC dust exposure and lowest $\mathrm{FEV}_{1}$ (adjusted for age, height, weight, and dust exposure) were examined. None had an observed FEV, less than $80 \%$ of the predicted value for age and height, and these men did not differ in symptoms, signs, or lung function from non-smokers with low dust exposure and similarly low $\mathrm{FEV}_{1}$. In a similar study of 18 smokers with the highest PVC dust exposures and lowest adjusted $\mathrm{FEV}_{1}$, some men had an observed $\mathrm{FEV}_{1}$ well below $80 \%$ of predicted values for non-smokers, but with one exception no clinical or functional differences were found between

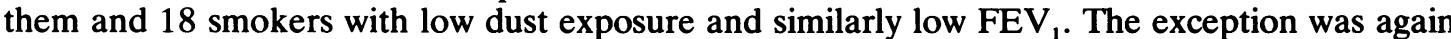
the presence of end inspiratory crackles on auscultation, which were slightly more frequent among men with the highest dust exposures (seven men) than among those with low exposure (two men, $\mathrm{p}<0.06$ ). We conclude that these findings are consistent with the suggestion that the radiographic abnormalities caused by PVC dust exposure are not associated with important functional effects or clinical illness. Further studies are desirable to examine the eventual outcome of the syndrome.

In a previous epidemiological study of 818 men sampled from the work force of a factory manufacturing polyvinylchloride (PVC), an index of individual cumulative exposure to respirable PVC dust was found to be related to the complaint of mild exertional dyspnoea, reduction of forced expiratory volume in one second $\left(\mathrm{FEV}_{1}\right)$, and forced vital capacity (FVC) and to the appearance of small rounded opacities on the chest radiograph.'

We have now studied men with small rounded

Address for reprint requests: Dr CA Soutar, Institute of Occupational Medicine, 8 Roxburgh Place, Edinburgh EH8 9SU.

Accepted 15 August 1983 opacities on their chest radiographs in more detail to determine whether any clinical or functional features are associated with these opacities. We have also studied men with low $\mathrm{FEV}_{1}$ drawn from those with high dust exposure to identify any characteristic clinical features which might be attributable to PVC dust exposure.

\section{Subjects and methods}

All the subjects were selected from 818 men examined at the factory in February 1979. An index of dust exposure had been calculated for these men on the basis of their occupational histories and on 
measurements of airborne respirable dust, ${ }^{\prime}$ and these estimates were used in selecting men for the clinical studies. The estimates represent an index of relative dust exposure rather than actual dust exposure, since only present dust levels are known.

\section{STUDY OF MEN WITH SMALL ROUNDED OPACITIES}

In the previous study one reader had recorded the presence of small rounded opacities $0 / 1$ or greater on the ILO U/C scale ${ }^{2}$ on the chest radiographs of 50 men. This reader's interpretations of the chest radiographic appearances have been used for the selection of men in the present study because only his readings showed the relationship of small rounded opacities to estimated exposure to PVC dust. He also recorded the highest number of radiographs showing these opacities. Ten of the 50 were of category $1 / 0$ or greater, and all these men were invited to attend for further study, together with a further 20 men randomly selected from the remainder. Seven of the men in category $1 / 0$ or greater agreed to take part in the survey, as did 18 of the 20 men in category $0 / 1$. Three reserve subjects with category $0 / 1$ were also invited and took part. These 28 men constituted the cases for the first study. In two of these men the reader thought irregular opacities were also present though of low category $(0 / 1)$. The five invited men who did not attend included four whose $F E V_{1}$ measured during the previous year had been more than half a litre less than that expected for their age and height.

The comparison group comprised men whose chest radiograph according to all three readers showed no small opacities of any type and they were matched with the cases by three ranges of index of PVC dust exposure, three ranges of age, smoking category, and employment (current employment at the factory, pensioner, or left for reasons other than retirement). By matching for these variables we were able to study effects related to the presence of small rounded opacities, independently of the effects of age, smoking, and dust. Twenty-nine subjects in this comparison group were seen. Eight invited men who did not attend included three whose $F E V_{1}$ measured during the previous year had been more than half a litre less than that expected for their age and height.

FURTHER STUDIES OF SUBJECTS WITH LOW FEV, In further studies not specifically related to small rounded opacities, we compared the clinical and physiological features of men with high dust exposures and low adjusted $\mathrm{FEV}_{1}$ with those of men with low dust exposures and low adjusted $F E V_{1}$, reasoning that the former group would be likely to include any men whose $\mathrm{FEV}_{1}$ had been seriously reduced by exposure to PVC dust, if such men existed, and that the latter group would consist of men whose FEV was low for reasons other than exposure to PVC dust. Any differences found between the groups might indicate differences between the patterns of disease caused by PVC dust and by other factors, thus possibly enabling individuals affected by exposure to PVC dust to be recognised.

Men were selected from the population remaining after exclusion of men in the first study. We calculated the adjusted $F E V_{1}$ by subtracting from the observed value the value predicted by multiple regression analysis based separately on the nonsmokers and the smokers in the population, allowing for other factors shown in the previous study to influence $\mathrm{FEV}_{1}$ (age, height, weight, employment status, and dust exposure).

\section{Non-smokers}

From non-smokers with an index of dust exposure greater than 10 years $\times \mathrm{mg} / \mathrm{m}^{3}$ (an arbitrary level used to separate those with higher exposures from those with average exposures) the 16 men with the lowest adjusted FEV 1 were selected. As a control group 16 non-smokers with similarly low adjusted $\mathrm{FEV}_{1}$, matched for age range, were selected from men with an index of dust exposure less than 3.5 units, a range representing low dust exposure.

\section{Smokers}

The final study included 20 cigarette smoking men with an index of dust exposure greater than 13.5 units and lowest adjusted $\mathrm{FEV}_{1}$, and a conrol group of 20 smoking men with an index of dust exposure less than 8.5 units and with similarly low values of adjusted $\mathrm{FEV}_{1}$ (smokers tended to have higher dust exposures than non-smokers).

\section{METHODS}

A medical team visited the factory and men were seen by appointment. None of the team knew to which study group any of the subjects belonged, nor had the men concerned been informed of their radiographic appearances at that time. This was because the appearances on the radiographs had been regarded previously, in a reading carried out for clinical purposes, as insufficiently serious to require notification to the individuals or clinical follow up. After the present study the men were told of their radiographic appearances and the health of their lungs was discussed with them. One of us (CAS) carried out a clinical examination of the chest, recording physical signs on a standard form. This was performed before the subject spoke about his symptoms or medical history, to avoid bias in the 
interpretation of physical signs. Subsequently the same observer gave each man a questionnaire on respiratory symptoms and medical history. The form of the questions on cough, sputum, recent exacerbations of cough and sputum, recent chest illness, breathlessness on exertion, and smoking history was identical to that in the Medical Research Council questionnaire of respiratory symptoms. ${ }^{3}$ The questionnaire additionally asked about personal history of asthma, hay fever, eczema, perennial rhinitis, pneumonia, acute bronchitis, and tuberculosis; childhood history of bronchitis, unduly frequent colds, tonsillitis, and ear infections; and first degree relatives' history of respiratory disease. Skinprick tests with mixed grass pollens, Dermatophagoides pteronyssinus, mixed house dust, and Aspergillus fumigatus (Bencard) were performed and read at 15 minutes. Weal diameters of $4 \mathrm{~mm}$ or more were taken as positive so long as the response to a control solution was $2 \mathrm{~mm}$ or less.

Forced expiratory flow volume curves were recorded on a rolling seal spirometer and an X-Y recorder during the breathing of air and again after three vital capacity breaths of a mixture of $80 \%$ helium and $20 \%$ oxygen. The curve selected for analysis was that with the greatest sum of forced

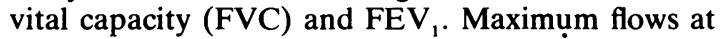
$50 \%$ and $25 \%$ of vital capacity on air $\left(\dot{\mathrm{V}} \max _{50}\right.$ and $\left.\dot{V} \max _{25}\right)$ and helium mixture $\left(\dot{\mathrm{V}} \max _{50 \mathrm{He}}\right.$ and $\dot{V} \max _{25 \mathrm{He}}$ ) and forced expiratory time were measured from these curves. Single breath carbon monoxide transfer factor (TLCO) was measured in duplicate with an automated spirometer system (PK Morgan Ltd). Effective alveolar volume $\left(\mathrm{VA}_{\text {eff }}\right)$ and TLCO were calculated for each manoeuvre and the means of the readings were analysed.

METHODS OF ANALYSIS

Tests of significance have been confined to $\chi^{2}$ tests, without continuity correction, for examination of the binary variables. The continuous variables (lung function measurements) were tested with independent two sample $t$ tests, equality of variances being assumed. It is recognised that when multiple comparisons are made on the same groups, as in the present case, some apparent differences will arise purely by chance. No allowance has been made for this or for the interrelationships of the many response variables. As an aid to the reader in interpreting the differences shown or suggested, $p$ values less than $0 \cdot 1$ have been quoted in the tables. In the study of men with small rounded opacities results for smokers, non-smokers, and ex-smokers have been analysed together, since the comparisons of interest were those between all these men and control subjects matched so far as possible by smoking habit as well as other factors. Ex-smokers were not included in the further studies not specifically related to small rounded opacities. Predicted values for $\mathrm{FEV}_{1}$ were based on multiple linear regression analysis with age and height allowed for in 148 non-smokers (excluding pensioners) studied in the previous epidemiological survey.

\section{Results}

\section{STUDY OF MEN WITH SMALL ROUNDED} OPACITIES

Twenty-eight men with small rounded opacities on the chest radiograph and 29 men without opacities $\overrightarrow{\vec{J}}$ were seen. Seventeen and 20 men respectively in these groups were current smokers, 10 and seven $\stackrel{\mathscr{D}}{\oplus}$ men ex-smokers, and one and two men respectively 은 non-smokers.

Men with small rounded opacities tended to admit to persistent phlegm production more often than men without opacities (table 1: nine of 28 men compared with one of 29 men, $p<0.01$ ). This was accompanied by a parallel but non-significant difference in persistent cough (nine and five men respectively). Small differences in numbers of complaints of dyspnoea and symptoms of recent chest illness, based on the questionnaire, did not reach significance. Childhood history of respiratory illness and family history of recurrent bronchitis (not shown in the table) were equally common in the two groups. There was a suggestion that crackles heard on auscultation in the late part of inspiration were more frequent in men with opacities than men without (seven of 27 men compared with two of 29 men $\mathrm{p}<0.06)$.

Differences in the mean observed results of the lung function measurements between men with and without opacities were trivial and non-significant (table 2). The mean difference in $\mathrm{FEV}_{1}$ between the groups was less than $200 \mathrm{ml}$, and was not significant in these small groups. It was consistent with that found to be related to the presence of small rounded opacities in the previous epidemiological study. ${ }^{1}$ The $\mathrm{FEV}_{1}$ values of 17 men-nine men with opacities and eight men without opacities-were less than $80 \%$ of the values predicted for age and height $\sigma$ (based on 148 non-smokers in the original study $N$ population). A few had substantial impairment of lung function likely to be associated with symptoms, but these men were not overrepresented among those with small rounded opacities (one man with opacities and two without had $\mathrm{FEV}_{1} \mathrm{~s}$ less than $60 \%$ of the predicted values).

STUDIES OF SUBJECTS WITH LOW FEV, The 13 non-smokers with lowest adjusted FEV, 
these groups (table 1). The medical histories did not suggest that these men were suffering from symptoms of any chronic respiratory disease.

After age and height differences had been allowed for no important or significant differences in lung function between these groups were apparent (table 2).

\section{SMOKERS WITH LOW FEV,}

Eighteen current cigarette smokers with low adjusted $\mathrm{FEV}_{1}$ and a high index of dust exposure were seen, and 18 smokers with low adjusted FEV and a low index of dust exposure. Respiratory symptoms were equally comrnon in the two groups, though a personal history of hay fever or perennial rhinitis was more common in the low exposure group (eight men) than in the high exposure group (two men, $p<0.03$ ). There was a suggestion that inspiratory crackles on auscultation were more common among men with high dust exposure (seven compared with two men, $\mathrm{p}<0.06$ ). Though both high and low dust exposure groups included many men with severe impairment of lung function of obstructive type, no substantial or significant differences in lung function between the groups were apparent (table 2).

\section{Discussion}

A previous study of 818 present and past workers at a factory making PVC had shown that estimates of exposure to respirable PVC dust were inversely related to FEV, and FVC after the effects of age and smoking had been allowed for, and were related to the prevalence of low categories of profusion of small rounded opacities in the chest radiographs. ${ }^{1}$ On that occasion one of three readers found that the prevalence of these opacities was related to dust exposure and independently to age. More recently these relationships have been confirmed by further independent readings of the radiographs (as yet unpublished).

In the present studies we have assessed the clinical importance of the above findings by examining some of the men most likely to have been affected by PVC dust. A good response was obtained from invited men, but the small number of non-attenders included some men with considerable impairment of lung function, both in those with radiographic abnormalities and in the comparative group. We do not know how much this may have affected the results, but the conclusions probably would not have been greatly altered if it had been possible to include these few non-attenders.

Men with small rounded opacities had an increased frequency of productive cough and of crackles on auscultation, indicating that the radiographic abnormalities were sometimes associated with other minor abnormalities of the lungs. The audible crackles tended to be of the end inspiratory type usually associated with diseases in which diffuse fibrosis of the lungs occurs. ${ }^{4}$ Despite this there was no evidence that more than trivial impairment of lung function was related to the presence of small rounded opacities after the effects of age, smoking, and dust exposure had been allowed for. The trivial impairment of function that was found was consistent with the results of the previous study. We do not know whether these radiographic abnormalities or the clinical features of affected men will change, and further studies of such men after an interval would be desirable.

In the studies of men with low $\mathrm{FEV}_{1}$ we wished to discover whether exposure to PVC dust could sometimes cause an impairment of lung function over and above the small average impairment related to dust exposure found in the original large epidemiological study. We chose to examine men whose impairment of function was more severe than could be explained by such factors as age, height and weight, and dust exposure (in these studies no adjustment was made for smoking habits: non-smokers and current cigarette smokers were studied separately, with non-smoking and smoking controls). To draw the conclusion that exposure to PVC dust had caused this impairment of function would require that men so affected (who would presumably tend to be found among those with the highest dust exposure) be distinguishable by their clinical features from men suffering from impairment of function from other causes (who should dominate the group with lowest dust exposures).

Among non-smokers with the lowest adjusted $\mathrm{FEV}_{1}$ values and highest dust exposures chronic respiratory symptoms were rare and lung function values were within normal limits, suggesting that (in non-smokers at least) PVC dust exposure at the levels experienced in this factory had not caused severe lung damage. Among smokers we found little difference in clinical features or type of functional defect between men with the highest dust exposure and those with low exposure. Auscultatory crackles of late inspiratory type may be found more frequently among men with the highest dust exposure and in men with small rounded opacities, but the finding of crackles seems insufficient evidence by itself on which to base a diagnosis of PVC dust induced disease in an individual. A history of hay fever or perennial rhinitis was more common among those with low dust exposure, but this could be the result of self-selection because men with such symptoms might take steps to reduce their exposure to 
dusty conditions.

It is not possible to recognise a syndrome induced by exposure to PVC dust in these individuals, and these studies provide no evidence that the excess impairment of function in these selected smokers was caused by exposure to dust.

In conclusion, the present studies provide further information on the clinical importance of the effects on the lung of exposure to PVC dust. The previous study showed that exposure to respirable PVC dust was related to the presence of small rounded opacities in the chest radiograph, and to a small average reduction of the $F E V_{1}$. The present clinical studies have shown that men with small rounded opacities are more likely to have bronchial mucous hypersecretion and to have late inspiratory crackles on auscultation than men without opacities. Serious illness or reduction of lung function have not been shown to be related to small rounded opacities or to exposure to PVC dust. The findings are in keeping with what is known about the histological appearances of the lungs of exposed animals and exposed workers, where accumulations of macrophages may be seen but fibrosis is not a prominent feature..$^{5-7}$

This study was carried out with the full cooperation of the management and work force of Imperial
Chemical Industries, to whom we are grateful for financial support. Further details of this work are recorded in Institute of Occupational Medicine Technical Memorandum TM/81/8.

\section{References}

' Soutar CA, Copland LH, Thornley PE, et al. Epidemiological study of respiratory disease in workers exposed to polyvinylchloride dust. Thorax 1980;35:644-52.

${ }^{2}$ International Labour Office. ILO U/C international classification of radiographs of the pneumoconioses, 1971. Geneva: ILO, 1972. (Occupational Safety and Health Series No 22.)

${ }^{3}$ Medical Research Council. Report of the working party on research into chronic bronchitis. London: Medical Research Council, 1976.

${ }^{4}$ Forgacs P. Lung sounds. London: Baillière Tindall, 1978.

${ }^{5}$ Frongia N, Spinazzola, Bucarelli A. Lesioni polmonari sperimentali da inalazione prolungate di PVC in ambiente di lavoro. Med Lav 1974;65:321-42.

- Szende B, Lapis K, Nemes A, Pinter A. Pneumoconiosis caused by the inhalation of polyvinylchloride dust. Med Lav 1970;61:433-6.

${ }^{7}$ Arnaud A, Pommier de Santi P, Garbe L, Payan H, Charpin J. Polyvinylchloride pneumoconiosis. Thorax 1978;33:19-25. 